\title{
Needlestick injury among interns and medical students in the Occupied Palestinian Territory
}

\author{
M. Al-Dabbas ${ }^{7}$ and N.M.E. Abu-Rmeileh ${ }^{2}$
}

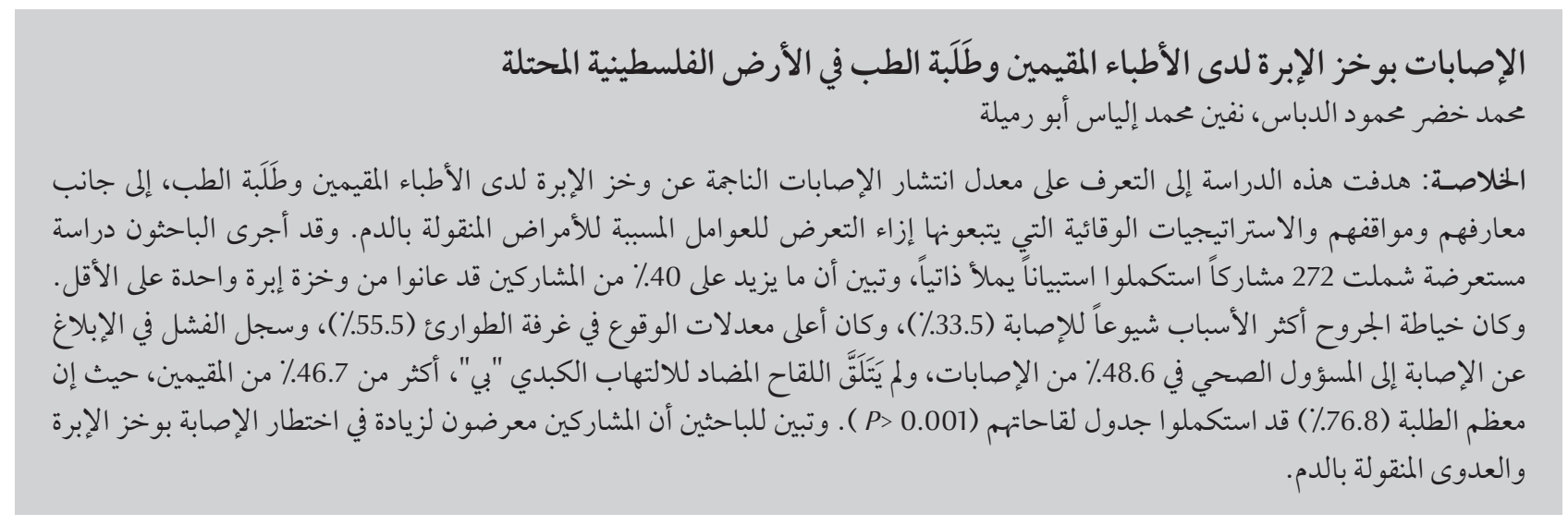

ABSTRACT The aim of this study was to determine the prevalence of needlestick injury (NSI) among interns and medical students as well as their knowledge of, attitude towards and their protective strategies against exposure to bloodborne pathogens. A cross-sectional study was conducted among 272 participants using a selfadministered questionnaire. Just over $40 \%$ of the participants had experienced at least 1 NSI. Wound suturing was the most common cause of injury (33.5\%), and the highest incidence (55.5\%) was in the emergency room. Failure to report the injury to health representatives was recorded for $48.6 \%$ of NSIs. Only $46.7 \%$ of the interns had received the hepatitis $B$ vaccine whereas most of the students $(76.8 \%)$ had completed their vaccination schedule $(P<0.001)$. Participants were found to be at a high risk of NSIs and bloodborne infections.

\section{Blessures par piqûre d'aiguille chez les internes et les étudiants en médecine en Territoire palestinien occupé}

RÉSUMÉ L'objectif de la présente étude était de déterminer la prévalence des blessures par piqûre d'aiguille chez les internes et les étudiants en médecine ainsi que les connaissances, les attitudes et les stratégies de protection contre l'exposition à des agents pathogènes à transmission hématogène. Une étude transversale a été menée auprès de 272 participants au moyen d'un auto-questionnaire. Un peu plus de 40 \% des participants avaient été blessés au moins une fois par piqûre d'aiguille. La cause la plus fréquente de ces blessures (33,5\%) était la suture des plaies, alors que l'incidence la plus forte était observée dans les services des urgences (55,5 \%). Dans 48,6 \% des cas, la blessure n'avait pas été notifiée aux responsables sanitaires. Seuls $46,7 \%$ des internes avaient reçu le vaccin contre l'hépatite $\mathrm{B}$, mais la plupart des étudiants (76,8 \%) étaient à jour dans leurs vaccinations $(P<0,001)$. Les résultats de l'étude indiquent que les participants sont confrontés à un haut risque de blessures par piqûre d'aiguille et d'infections hématogènes.

'Department of Continuing Education, Al-Quds University Medical School, Jerusalem, West Bank, Palestine (Correspondence to M. Al-Dabbas: aldabbass@yahoo.com).

${ }^{2}$ Institute of Community and Public Health, Birzeit University, Birzeit, West Bank, Palestine.

Received: 16/08/10; accepted: 28/11/10 


\section{Introduction}

One of the most serious threats healthcare workers face during their clinical practice is the possibility of exposure to deadly viruses. They are exposed to preventable injuries involving over 20 different bloodborne pathogens resulting in about 1000 infections per year, of which the most common are hepatitis $B$ virus $(\mathrm{HBV})$, hepatitis $\mathrm{C}$ virus (HCV) and human immunodeficiency virus (HIV) [1]. Accidental needlestick injuries (NSI) are an occupational hazard for health-care workers: more than 100000 injuries are reported in hospitals in the United Kingdom annually [2] and 600 000-800 000 in the United States of America. However, at least half of all such injuries are believed to go unreported $[3,4]$. According to the World Health Organization, 16000 cases of Hepatitis C, 66000 cases of Hepatitis B and 1000 cases of HIV may have occurred worldwide in the year 2000 among health-care workers through exposure to NSIs [5].

In the last few years, worldwide statistics on needlestick injuries have become more precise; several benchmark numbers are lower than previously thought [3]. Despite this, NSI remains one of the hidden problems for health-care workers in some countries, including Palestine, where it is also very prevalent [6-8]. A study done in Canada has shown that $70 \%$ of nurses, $47 \%$ of technicians, $78 \%$ of residents and $74 \%$ of laboratory technicians were exposed to the dangers of NSI [9].

In November 2002, World Health Report data indicated that $2.5 \%$ of HIV and $40 \%$ of hepatitis B and C cases among health-care workers worldwide were the result of occupational exposure [10].

Hepatitis B is the most important infectious occupational hazard for health-care workers and medical students in the Occupied Palestinian Territory since it is situated in area of intermediate endemicity for HBV carriers [11], while the Gaza Strip is considered an endemic area [12]. For HBV, the risk of pathogen transmission with a sharp object has been estimated to be $6 \%-30 \%$; for $\mathrm{HCV}$ it is $5 \%-10 \%$ and for HIV 0.3\% [13-15]. Post-exposure prophylaxis is shown to be effective in $75 \%$ to over $90 \%$ of cases for $\mathrm{HBV}$; for HIV, the risk of infection is reduced. So far, there is still no known means of preventing $\mathrm{HCV}$ acquisition following NSI [13].

The emotional impact of an NSI can be severe and long-lasting, even when a serious infection is not transmitted. Yet the problem of exposure to contaminated blood among health-care workers, especially interns and medical students, has received inadequate attention in the Occupied Palestinian Territory.

The aim of this study was to determine the prevalence and selected determinants of NSIs among interns and medical students in the Occupied Palestinian Territory as well as their knowledge, attitude and protective strategies used against exposure to bloodborne pathogens. We conducted this study with the hypothesis of a high prevalence of NSI among interns and medical students owing to lack of knowledge and carelessness.

\section{Methods}

In this cross-sectional study, the participants comprised 137 interns working in 9 hospitals in 6 governorates in the Occupied Palestinian Territory and 135 medical students enrolled in the 3 Palestinian medical schools (Al-Quds, Annajah and Al-Azhar) (58 from 5th year and 77 from 6 th year) during their clinical practice (Table I). We targeted all interns and medical students during their clinical practice. Response rate was (272/339) 80\%. Students on sick leave, or travelling during the study period were excluded.
Anonymous, self-administered questionnaires were distributed among the participants over a period of 2 months (February and March, 2009). Medical students who were not in their clinical practice distributed the questionnaire and explained the objectives of the study to the participants. They then collected all the questionnaires and sent them back to the main researcher, who was responsible for the coding and data entry. The participants (the 3 groups) were asked to recall all their past experiences of needlestick injuries (NSI) and the surrounding circumstances since the start of their clinical practice. This was 4 years for the interns (starting from the fourth year in medical school), 3 years for sixth year students and 2 years for fifth year students.. Questions pertaining to self-perceived cause of injury and knowledge of bloodborne diseases, NSI reporting and personal protection, assuming the availability of protective measures, were also asked.

The questionnaire was designed based on several studies and questions propounded in various references $[3,5,6]$ and it was piloted on 11 randomly selected individuals (6 medical students in Al-Quds University, and 5 interns from 2 hospitals; none of whom was included in the study sample) and the questions were modified accordingly.

In this study NSI was defined as an injury caused by a sharp instrument, including, but not limited to, needles, scalpels and contaminated broken glass, which are potentially contaminated with the body fluid of another person [16]. Cases of NSI were respondents who had had at least 1 experience of NSI; the number of injuries they experienced was also counted.

The data were analysed using SPSS, version 15; the associations between the dependent variable (NSI) and the selected independent variables were tested using the chi-squared test for categorical variables with alpha set at $5 \%$. 


\section{Results}

A total of 272 questionnaires (of 339) were completed, 137 (50.4\%) were interns (response rate 84\%), 77 (28.3\%) were 6 th year and $58(21.3 \%)$ were 5 th year medical students (overall response rate $77 \%$ for medical students). The overall response rate was $80.2 \%$.Mean age was 24.8 (standard deviation = 2.75 ) years: $56.2 \%$ of the participants were male and $43.8 \%$ female.

Since the beginning of their clinical practice, $41.2 \%$ of all respondents had experienced at least 1 NSI: $57.7 \%$ of the interns, $28.6 \%$ of 6 th year and $19.0 \%$ of 5th year medical students (Table 1).

The relation between education level (intern versus medical student) and NSIs was statistically significant $(P \leq 0.001)$ (Table 1$)$, as opposed to sex: prevalence of NSI among male students was $24.2 \%$ compared to $25.8 \%$ for female students $(P=0.83)$, and $52.4 \%$ among male interns compared to $65.2 \%$ for female interns $(P=0.16)$. The results show that $34.2 \%$ (38) of the injured participants had had 1 NSI, $37 \%$ (41) had had 2, 13.5\% (15) had had 3 , and $15.3 \%$ (17) had had more than 3 .

Of the 239 injuries recalled, cause was reported for 179 cases (Table 2). Wound suturing was specifically cited as the cause of injury in 60 cases (33.5\%). Injury during intramuscular injection accounted for $20.7 \%$, followed by recapping needles (18.4\%). The habit of recapping used needles was reported by $71.6 \%$ (192) of the respondents.

The highest incidence of NSIs was found in the emergency room (55.5\%), followed by obstetrics (15.0\%) and surgery wards (9.6\%) (Table 2).

The most common post-exposure action taken by the injured personnel was washing and disinfection with povidone iodine solution (63.1\%), followed by only washing the site of injury (16.2\%); 7.2\% did nothing after being exposed to NSI.
Almost 50\% of all NSIs were not reported to occupational health departments, mostly because the injured person did not know to whom or to where the injuries should be reported (29.5\%), or did not know it should be reported (27.7\%) (Table 3). Interns (37.3\%) were statistically significantly less likely to report needlestick injuries than medical students $(66.0 \%)(P<0.01)$.

Of those who did not experience NSI during their clinical practice, 37.9\% of the interns and $70.6 \%$ of the medical students believed this was because they did few procedures, whereas $33.8 \%$ of all the participants cited extreme care to be the reason for not being injured.

The majority of respondents did not routinely use gloves when administering intramuscular (77.0\%) or intravenous (59.7\%) medications, or during intravenous cannulation (57.3\%) (Table 4). Gloves are commonly worn for inspecting wounds (89.2\%), and almost always for wound suturing (95.9\%). Glove usage did not vary with education level: usage by interns, and 5th and 6th year medical students was similar.

Additionally, $53.2 \%$ of the participants did not use the double glove technique because they believed that wearing 2 gloves decreases hand sensation (31.6\%). Some believed that the double glove technique does not increase protection (25.7\%); others just followed the example of other health professionals who did not wear double gloves (22.8\%) (Table 5). The relationship between wearing 2 gloves and education level was not statistically significant $(P=0.09)$.

Most of the participants (87.0\%) reported that they always used sharps containers to dispose of needles as $19.4 \%$ practiced recapping sometimes or rarely and only $9.0 \%$ never recap needles. In addition, eye protection was not used routinely by the majority (97.0\%) of the participants.

Only 64 interns (46.7\%) had received the hepatitis $B$ vaccine while $81.6 \%$ of 6 th-year medical students and

\begin{tabular}{|c|c|c|c|}
\hline \multirow{2}{*}{ Participants } & \multirow[t]{2}{*}{ No. } & \multicolumn{2}{|c|}{ NSIs } \\
\hline & & No. & $\%$ \\
\hline \multicolumn{4}{|l|}{ Interns } \\
\hline Tulkarem & 13 & 10 & 76.9 \\
\hline Nablus & 23 & 14 & 60.9 \\
\hline Ramallah & 20 & 13 & 65 \\
\hline Jerusalem & 15 & 8 & 53.3 \\
\hline Hebron & 35 & 20 & 57.1 \\
\hline Gaza & 31 & 14 & 45.2 \\
\hline Total & 137 & 79 & 57.7 \\
\hline \multicolumn{4}{|c|}{ 5th year medical students } \\
\hline Al-Quds SoM & 27 & 3 & 11.1 \\
\hline Al-Azhar SoM & 13 & 3 & 23 \\
\hline Annajah SoM & 18 & 5 & 27.8 \\
\hline Total & 58 & 11 & 19 \\
\hline \multicolumn{4}{|c|}{ 6th year medical students } \\
\hline Al-Quds SoM & 33 & 8 & 24.2 \\
\hline Al-Azhar SoM & 25 & 7 & 28 \\
\hline Annajah SoM & 19 & 7 & 36.8 \\
\hline Total & 77 & 22 & 28.6 \\
\hline
\end{tabular}

SoM $=$ School of Medicine . 


\begin{tabular}{|c|c|c|c|c|c|c|c|c|}
\hline \multirow[t]{3}{*}{ Variable } & \multicolumn{8}{|c|}{ Occurrence of injury } \\
\hline & \multicolumn{2}{|c|}{ Interns } & \multicolumn{2}{|c|}{ 6th year students } & \multicolumn{2}{|c|}{ 5th year students } & \multicolumn{2}{|c|}{ Total } \\
\hline & No. & $\%$ & No. & $\%$ & No. & $\%$ & No. & $\%$ \\
\hline \multicolumn{9}{|l|}{ Cause of injury ${ }^{a}$} \\
\hline Wound suturing & 43 & 33.6 & 12 & 35.3 & 5 & 29.4 & 60 & 33.5 \\
\hline IM drug injection & 27 & 21.1 & 8 & 23.5 & 2 & 11.8 & 37 & 20.7 \\
\hline Recapping needles & 24 & 18.7 & 5 & 14.7 & 4 & 23.5 & 33 & 18.4 \\
\hline Insertion of IV cannula & 11 & 8.6 & 4 & 11.8 & 4 & 23.5 & 19 & 10.7 \\
\hline IV drugs or venesection & 11 & 8.6 & 4 & 11.8 & 1 & 5.9 & 16 & 8.9 \\
\hline Arterial blood for $\mathrm{ABG}$ & 3 & 2.3 & 0 & 0 & 1 & 5.9 & 4 & 2.2 \\
\hline Subcutaneous injection & 2 & 1.6 & 0 & 0 & 0 & 0 & 2 & 1.1 \\
\hline Other & 7 & 5.5 & 1 & 2.9 & 0 & 0 & 8 & 4.5 \\
\hline Total & 128 & 100.0 & 34 & 100.0 & 17 & 100.0 & 179 & 100.0 \\
\hline \multicolumn{9}{|l|}{ Location } \\
\hline Emergency room & 59 & 54.6 & 13 & 50 & 9 & 75.1 & 81 & 55.5 \\
\hline Obstetrics department & 15 & 13.9 & 6 & 23.1 & 1 & 8.3 & 22 & 15 \\
\hline Surgery department & 12 & 11.1 & 1 & 3.8 & 1 & 8.3 & 14 & 9.6 \\
\hline Operating room & 5 & 4.6 & 4 & 15.4 & 0 & 0 & 9 & 6.2 \\
\hline Outpatient clinic & 7 & 6.5 & 0 & 0.0 & 0 & 0.0 & 7 & 4.8 \\
\hline Department of Internal Medicine & 6 & 5.6 & 0 & 0.0 & 0 & 0.0 & 6 & 4.1 \\
\hline Patients' room & 3 & 2.8 & 2 & 7.7 & 1 & 8.3 & 6 & 4.1 \\
\hline $\mathrm{CCU} / \mathrm{ICU}$ & 1 & 0.9 & 0 & 0.0 & 0 & 0.0 & 1 & 0.7 \\
\hline Total & 108 & 100.0 & 26 & 100.0 & 12 & 100.0 & 146 & 100.0 \\
\hline
\end{tabular}

${ }^{a}$ Missing data: cause was not reported for 60 injuries.

$I M=$ intramuscular: $I V=$ intravenous: $A B G=$ arterial blood gases; $C C U=$ cardiac care unit; $I C U=$ intensive care unit.

$71.9 \%$ of 5 th-year medical students had completed their vaccination process $(P$ $<0.001$ ); the remaining $53.1 \%$ of interns and $23.2 \%$ of medical students had not started (18.9\%) or had not completed (19.3\%) the vaccination process. The reasons included being already positive to $\mathrm{HBV}$ antibodies, being busy on the day of the vaccination, or simply forgetting; others claimed that it is the responsibility of health authorities to arrange and announce for the vaccination programmes. The relationship between receiving the hepatitis $B$ vaccine and education level was statistically significant $(P=0.006)$.

The majority of the participants (76.3\%) said they had acquired knowledge of bloodborne diseases mainly through formal lectures in their medical schools and 23\% from books.

In our study, $51.5 \%$ oftheparticipants considered their level of knowledge of what should be done after exposure to NSI to be insufficient. Only $34.2 \%$ stated they had learnt the proper way of performing medical procedures in medical school, while $43.5 \%$ did so from observing other health-care workers.

\section{Discussion}

The results of our study are in agreement with the results of a study on medical students in France, where 24\% had at least 1 experience of NSI,Wound suturing accounted for $58 \%$ of these injuries [17]. In a Washington study, $30 \%$ of medical students had at least 1 experience of NSI and most of the injuries occurred in the operating room [7]. In addition, most of the students (61.9\%) in a Taiwan study had NSI, and the majority of the injuries occurred in patient's rooms [8].
This is also in agreement with a study from New York (27\% of students had at least 1 NSI) [18], and with the studies by Norsayani and Noor Hassim [6], Abu-Gad and Al-Turki [19] and Jepsen and Smith [20] in which the frequency of injury in medical students was reported at $22.0 \%-35.5 \%$. Other studies on medical students have reported 51.9\%-83\% for NSI [15].

One of the main factors causing different numbers of NSI cases may be the definition in different studies. In many studies, injuries from all types of sharp pointed instruments were under consideration; however, in others only hollow-needle instruments were taken into account. The general definition we followed in our study will give a higher percentage compared to the specific definition used in other studies.

In our study, the most common reason for not reporting NSIs was the lack 


\begin{tabular}{|c|c|c|c|c|c|c|c|c|}
\hline \multirow[t]{2}{*}{ Reason for not reporting } & \multicolumn{2}{|c|}{ Interns } & \multicolumn{2}{|c|}{ 6th year students } & \multicolumn{2}{|c|}{5 th year students } & \multicolumn{2}{|c|}{ Total } \\
\hline & No. & $\%$ & No. & $\%$ & No. & $\%$ & No. & $\%$ \\
\hline Do not know to whom or where it should be reported & 21 & 28.4 & 9 & 36.0 & 3 & 23.1 & 33 & 29.5 \\
\hline Do not know it should be reported & 18 & 24.3 & 6 & 24.0 & 7 & 53.8 & 31 & 27.7 \\
\hline Believe reporting would not influence the outcome & 21 & 28.4 & 7 & 28.0 & 1 & 7.7 & 29 & 25.9 \\
\hline Forgot & 14 & 18.9 & 3 & 12.0 & 2 & 15.4 & 19 & 17.0 \\
\hline Total & 74 & 100.0 & 25 & 100.0 & 13 & 100.0 & 112 & 100.0 \\
\hline
\end{tabular}

of knowledge to whom or where injuries should be reported and lack of knowledge that all injuries had to be reported. Here we have 2 points to discuss: first the preparation of medical students and how to protect themselves. i.e. a criticism of the curricula used in medical universities. Second, internal hospital regulations should be explained to students and interns before they get in contact with patients. This needs to be discussed with the relevant authorities to make it applicable for all health-care workers in the Occupied Palestinian Territories.

One other important issue is that about a quarter of the respondents believed that reporting was not important and would not influence the outcome. This is serious since it indicates that those respondents are not careful enough about their health and so don't care about protective measures. This might lead to other malpractices, which may affect patients' health in addition to their own.

The observed high level of underreporting suggests that the students' need for education on prevention, and especially on the importance of reporting all NSIs and the possibility of prophylaxis after exposure to bloodborne pathogens $[8,13,14]$, because when a health-care worker suffers a needlestick injury, not only is he/she exposed to the risk of disease, but so are his/her future patients. In order to safeguard patients, it is imperative that interns and medical students report NSIs.

The rates for glove use were similar to rates previously demonstrated in North America [9,16,21]. Whitby and McLaws found that $43 \%$ of healthcare workers always wore gloves when venesecting [21]; this was $40.3 \%$ in our study. In a study on French medical students, $91 \%$ always wore gloves during wound suturing [17]; in our study, the great majority of interns and medical students did appear to wear gloves for wound suturing (95.9\%) and/or inspection (89.2\%), where the risk of contamination with body fluids is high.

The most common department in which the participants had the experience of an NSI was the emergency department, followed by the obstetrics and surgical departments, mostly during wound suturing, intramuscular injection and recapping needles. In a French study, it was reported that most of the injuries (58\%) took place while suturing wounds [17], while recapping needles was the commonest cause of injury in some other studies $[9,21]$. The gynaecology ward, the emergency room and the surgery ward have also been reported as being common departments for NSIs $[6,22]$. Recapping of used needles was a common practice among interns and medical students in our sample, despite specific guidelines laid down by the health authorities.

The present study showed that $53.3 \%$ of interns, $18.4 \%$ of 6 th-year medical students and $28.1 \%$ of 5 th-year medical students were not vaccinated against hepatitis B. In a 2001 Danish study of 406 medical students, $34 \%$ were not vaccinated against hepatitis B [20].

We found that $50 \%$ of the interns and $56.4 \%$ of medical students did not use the double glove technique because of decreased hand sensation and lack of belief in its benefits. This is in agreement with a study on medical students in Strasburg, in which 50\% did not use 2 gloves because of the decrease in sensation and lack of belief in the benefits [23]. Norsayani and Noor Hassimalso found $75 \%$ of physicians stated they did not us 2 gloves, despite being aware of

\begin{tabular}{|c|c|c|c|c|c|c|c|c|}
\hline \multirow[t]{2}{*}{ Type of procedure } & \multicolumn{2}{|c|}{ Interns } & \multicolumn{2}{|c|}{ 6th year students } & \multicolumn{2}{|c|}{ 5th year students } & \multicolumn{2}{|c|}{ Total } \\
\hline & No. & $\%$ & No. & $\%$ & No. & $\%$ & No. & $\%$ \\
\hline IM injection & 29 & 21.3 & 18 & 23.4 & 15 & 26.8 & 62 & 23.0 \\
\hline IV injection & 57 & 41.9 & 28 & 36.8 & 23 & 41.1 & 108 & 40.3 \\
\hline IV cannula insertion & 65 & 47.8 & 28 & 37.3 & 21 & 37.5 & 114 & 42.7 \\
\hline Wound inspection & 123 & 90.4 & 65 & 85.5 & 51 & 91.1 & 139 & 89.2 \\
\hline Wound suturing & 131 & 96.3 & 71 & 93.4 & 55 & 98.2 & 257 & 95.9 \\
\hline
\end{tabular}

$I M=$ intramuscular $; I=$ intravenous. 


\begin{tabular}{|c|c|c|c|c|c|c|c|c|}
\hline \multirow[t]{2}{*}{ Reason } & \multicolumn{2}{|c|}{ Interns } & \multicolumn{2}{|c|}{$\begin{array}{l}\text { 6th year } \\
\text { students }\end{array}$} & \multicolumn{2}{|c|}{$\begin{array}{l}\text { 5th year } \\
\text { students }\end{array}$} & \multicolumn{2}{|c|}{ Total (\%) } \\
\hline & No. & $\%$ & No. & $\%$ & No. & $\%$ & No. & $\%$ \\
\hline Decreased hand sensation & 18 & 28.2 & 14 & 35.0 & 11 & 34.3 & 43 & 31.6 \\
\hline Belief that double gloving did not increase protection & 21 & 32.8 & 7 & 17.5 & 7 & 21.9 & 35 & 25.7 \\
\hline Follow other HCW who did not wear double gloves & 14 & 21.9 & 9 & 22.5 & 8 & 25.0 & 31 & 22.8 \\
\hline Inadequate facilities & 4 & 6.3 & 6 & 15.0 & 3 & 9.4 & 13 & 9.6 \\
\hline Other & 7 & 10.8 & 4 & 10.0 & 3 & 9.4 & 14 & 10.3 \\
\hline Total & 64 & 100.0 & 40 & 100.0 & 32 & 100.0 & 136 & 100.0 \\
\hline
\end{tabular}

HCW $=$ health-care worker .

the benefits [6]. Our study showed only $3.0 \%$ of the respondents using eye protection which is similar to the results in another study on medical students in which only $2.5 \%$ used eye protection in the operating theatre or the emergency room [22].

A study on medical undergraduates showed that $67.4 \%$ of the students recapping needles after use were not aware of the correct practice and were just following the example of other health workers [24]. We found that $74.3 \%$ of interns and $70.6 \%$ of medical students always recap needles.

The reliability of the reported rate of needlestick injuries in our study is limited by the differential recall ability of the respondents. However, it is reasonable to assume a fairly accurate recall since a needlestick injury is usually a painful experience [25].

\section{Conclusion}

NSIs are common among interns and medical students in the Occupied Palestinian Territory, particularly among interns, who most likely have a greater workload and may therefore be at greater risk. Therefore, preventive measures should be taken into consideration by the relevant authorities and universities. Also, focusing on the importance of reporting an NSI and the possibility of prophylactic measures seems necessary. Setting up an NSI management centre in hospital wards and follow-up of the injured individuals are recommended.

On the other hand, adherence to the universal precautions of using gloves and disposing of sharps was not optimal, especially among interns, suggesting a need to educate them more carefully on safe practices and the need for setting up postgraduate training courses on occupational risk management.

\section{Acknowledgements}

The authors wish to thank Professor Ziad Abdeen for his assistance and directions We also appreciate the contributions of all interns and medical students who participated in this study. Our grateful thanks also go to the following doctors and medical students for their great assistance in distributing and collecting the questionnaires in different governorates in our occupied land in the West Bank and Gaza; they are Fawwaz Awwad, Layali Qaddoumi, Samaa Al-Mulk, Mohammad AlQadi, Samed Jabareen, Nadera Damsa, Tawfeeq ElShoubaky, Khadeeja Faroun, Saleem ElJa'bary, Rana Al-Taweel, Taha Qaraqe' and Imadeddin Abu Shkheidem.

\section{References}

1. Bolyard EA al. Guidelines for infection control in health care personnel. American Journal of Infection Control, 1998, 26(3):289-354.

2. The global needle crisis (sharps injury information). San Francisco, San Francisco Chronicle, 1998 (http://www.sfgate. com/news/special/pages/1998/04/needles/, accessed 25 May 2012]).

3. Perry MA, Jagger J. Healthcare worker blood exposure risks: correcting some outdated statistics. Advances in Exposure Prevention, 2003, 6(3):28-31.

4. Tereskerz PM, Pearson RD, Jagger J. Occupational exposure to blood among medical students. New England Journal of Medicine, 1996, 335:1150-1153.

5. Pruss-Ustun A, Rapiti E, Hutin Y. Estimation of the global burden of disease attributable to contaminated sharps injuries among health-care workers. American Journal of Industrial Medicine, 2005, 48(6):482-490.

6. Norsayani MY, Noor Hassim I. Study on incidence of needle stick injury and factors associated with this problem among medical students. Journal of Occupational Health, 2003, 45(3):172-178.

7. Patterson JM et al. Needlestick injuries among medical students. American Journal of Infection Control, 2003, 31(4):226230.

8. Shiao JS et al. Student nurses in Taiwan at high risk for needlestick injuries. Annals of Epidemiology, 2002, 12(3):197-201.

9. Needlestick injuries. Hamilton, Canada, Centre for Occupational Health and Safety, 2004 (http://www.ccohs.ca/ oshanswers/diseases/needlestick_injuries.html, accessed 25 May 2012) 
10. World health report 2002: reducing risks, promoting healthy life Geneva, World Health Organization, 2002 (http://www.who. int/whr/2002/en/index.html).

11. Nashef L, Thalji A. Hepatitis B serology among the Palestinian population. Annals of Tropical Pediatrics, 1992, 12(3):321-325.

12. Kuhail S, El-Khodary R, Ahmed F. Evaluation of the routine hepatitis B immunization programme in Palestine. Eastern Mediterranean Health Journal, 2000, 6(5-6):864-869.

13. NIOSH publications and products. Selection, evaluation and using sharps disposal containers. [Website]. Atlanta, Centers for Disease Control and Prevention, 1999 (http://www.cdc.gov/ niosh/docs/97-111/, accessed 25 May 2012).

14. Askarian M, Ghavanini AA. Survey on adoption of measures to prevent nosocomial infection by anaesthesia personnel. Eastern Mediterranean Health Journal, 2002, 8(2-3):416-421.

15. Perdue B et al. HIV-1 transmission by a needle-stick despite rapid initiation of four-drug postexposure prophylaxis. Program and abstracts of the 6th Conference on Retroviruses and Opportunistic Infections, Chicago 31 January-4 February 1999. Foundation for Retrovirology and Human Health in scientific collaboration with the National Institute of Allergy and Infectious Diseases and CDC, 1999:107.

16. Needle stick injuries. Bandolier (Bandolier Extra), 2003 (http:// www.medicine.ox.ac.uk/bandolier/Extraforbando/needle. pdf, accessed 25 May 2012).

17. Rosenthal E et al. Needlestick injuries among French medica students. Journal of the American Medical Association, 1999, 281:1660.
18. Resnic FS, Roberts RB, Davis JM. Occupational exposures among medical students and house staff at a New York City medical center. Archives of Internal Medicine, 1995, 155(1):7580

19. Abu-Gad HA, Al-Turki KA. Some epidemiological aspects of needle stick injuries among the hospital health-care workers: Eastern Province, Saudi Arabia. European Journal of Epidemiology, 2001, 17(5):401-407.

20. Jepsen MP, Smith E. Needlestick injuries among medical students at the University of Copenhagen. A questionnaire study in 2001. Ugeskr Laeger, 2003, 165(22):2273.

21. Whitby RM, McLaws ML. Hollow-bore needlestick injuries in a tertiary teaching hospital: epidemiology, education and engineering. Medical Joutnal of Australia, 2002 Oct 21, 177(8):418422.

22. Cervini $P$, Bell C. Brief report: needlestick injury and inadequate postexposure practice in medical students. Journal of General Internal Medicine, 2005, 20(5):419-421.

23. Meunier $\mathrm{O}$ et al. Blood exposure accidents among medical students. Médecine et Maladies Infectieuses, 2001, 31(9):537543.

24. Naing NN, Zulkifli A, Kamaruzzaman I. Puncture injuries during undergraduate medical training. Journal of the Islamic Medical Association of North Africa, 1999, 31(3):270-273.

25. Chia HP et al. A study of needle-stick injuries among house officers in a major hospital. Singapore Medical Journal, 1994, 35:41-43.

\section{WHO best practices for injections and related procedures toolkit}

Medical treatment is intended to save life and improve health, and all health workers have a responsibility to prevent transmission of health-care associated infections. Adherence to safe injection practices and related infection control is part of that responsibility - it protects patients and health workers.

The above-mentioned toolkit covers elements of standard precautions relevant to the transmission of bloodborne pathogens through unsafe injection practices in health-care settings. The document will help to increase health workers' awareness of the importance of standard precautions relevant to injection safety.

The main areas covered by the toolkit are: bloodborne pathogens transmitted through unsafe injection practices; relevant elements of standard precautions and associated barrier protection; best injection and related infection prevention and control practices; occupational risk factors and their management.

This document is available at: http://www.who.int/injection_safety/toolbox/9789241599252/en/index.html 